Bulletin d'études orientales

\title{
العروض العربي في القرن الثالث عشر بعد الخليل بين التقليد والتجديد
}

\author{
ديمة الشكر et برونو باولي
}

\section{(2) OpenEdition}

Édition électronique

URL : http://journals.openedition.org/beo/221

DOI : $10.4000 /$ beo.221

ISBN : 978-2-35159-318-9

ISSN : 2077-4079

\section{Éditeur}

Presses de l'Institut français du Proche-Orient

Édition imprimée

Date de publication : 1 octobre 2010

Pagination : 7-11

ISBN : 978-2-35159-170-3

ISSN : 0253-1623

Référence électronique

Bulletin d'études orientales [En ligne], Tome LIX | octobre 2010, mis en ligne le 01 octobre 2011, consulté le 31 janvier 2020. URL : http://journals.openedition.org/beo/221 ; DOI : 10.4000/beo.221 
الندوة، تبرهن على ذلك، كما تبرهن أنه وبعد مرور أكثر من ثلاثة عشر قرناً على استقراء الخليل

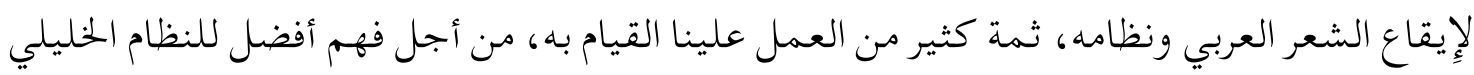

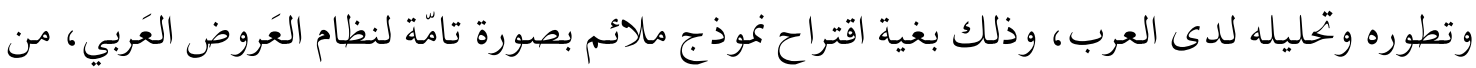

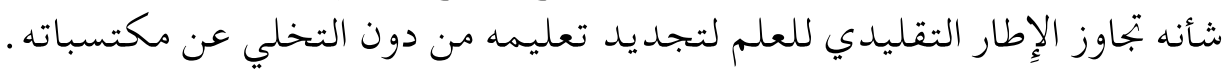

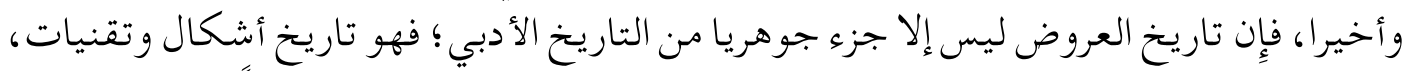

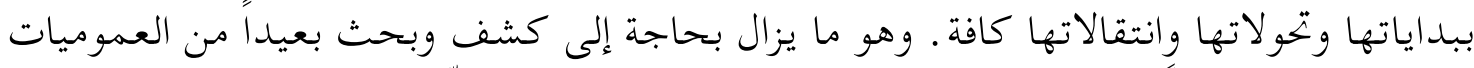

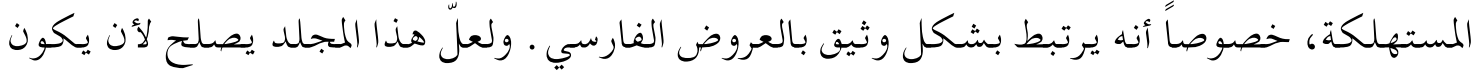

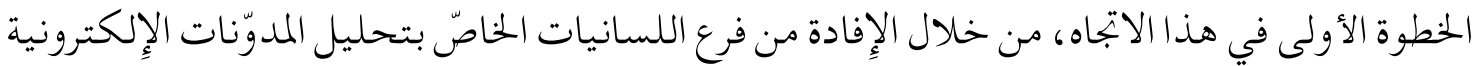

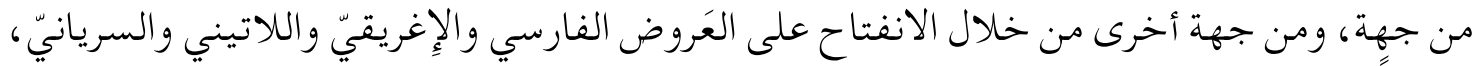

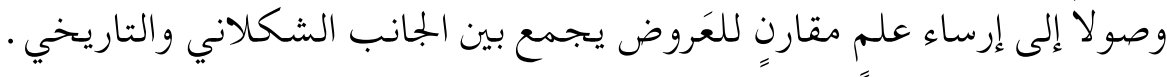


يتعلّق بالسناد في القافية، وغيرها من الأمور التي تكشف في مجملها عن وجود تفاعل أصيل بين

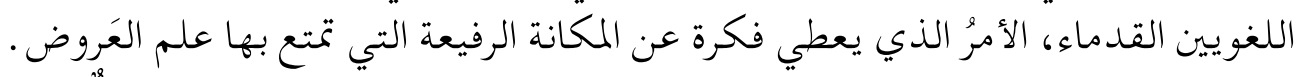

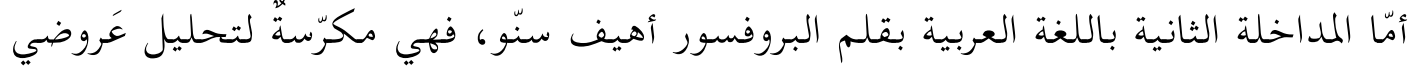

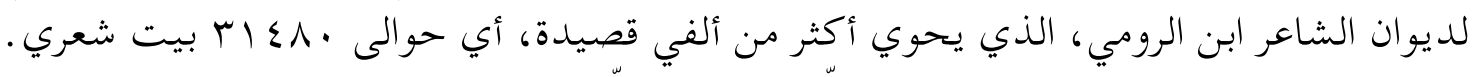

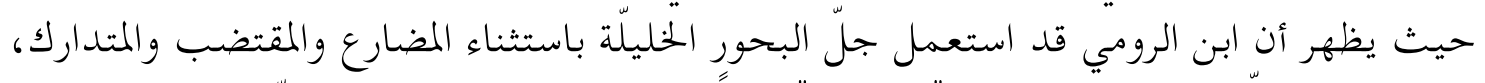

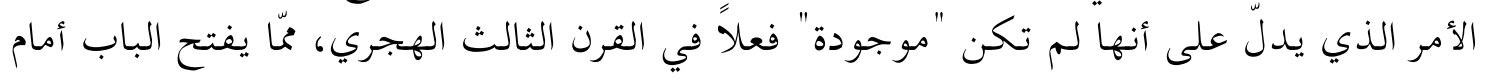

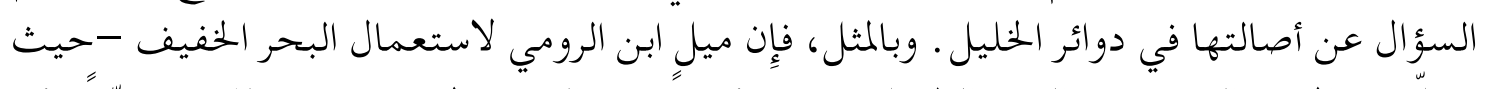

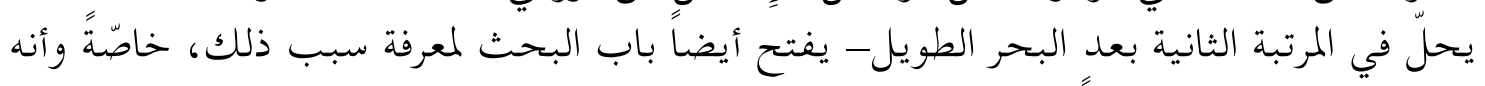

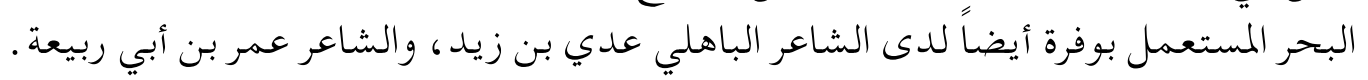

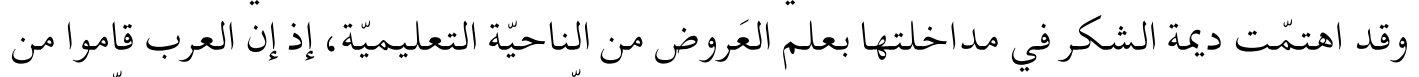

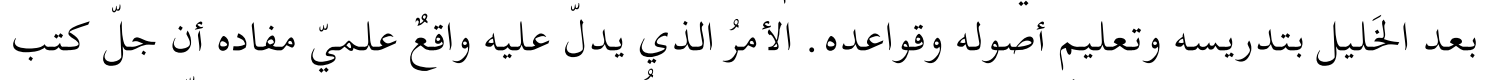

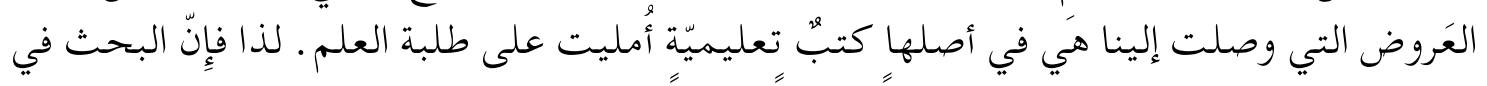

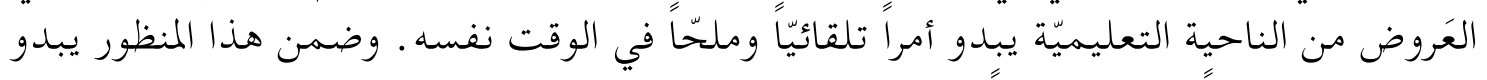

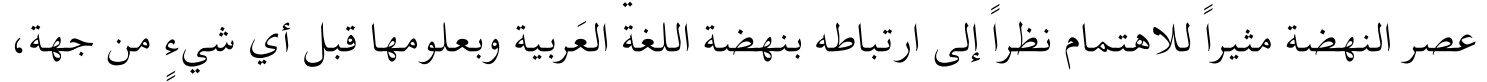

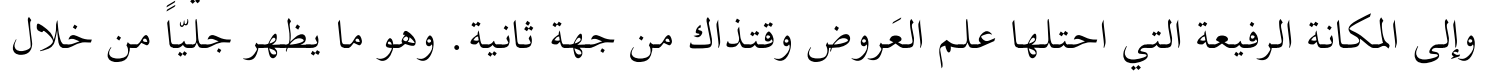

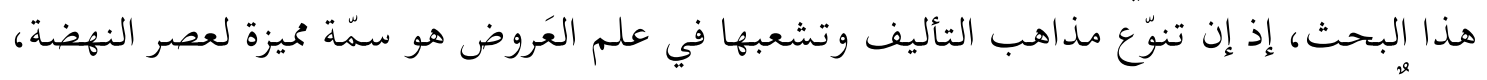

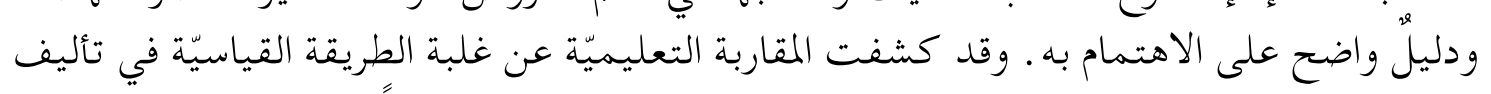

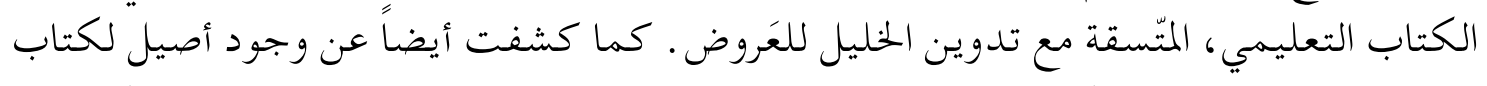

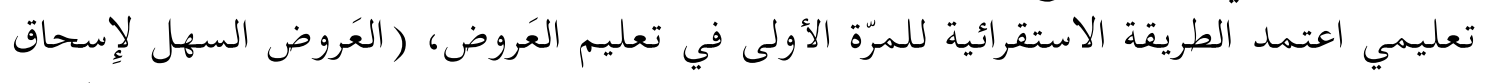

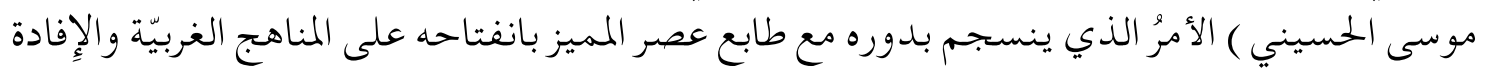
منها مونا

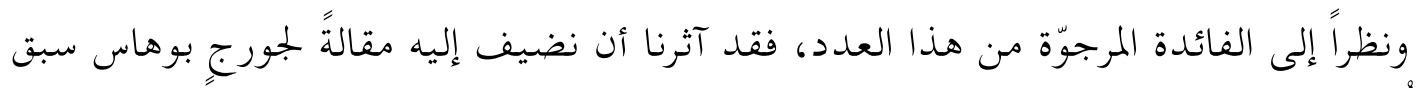

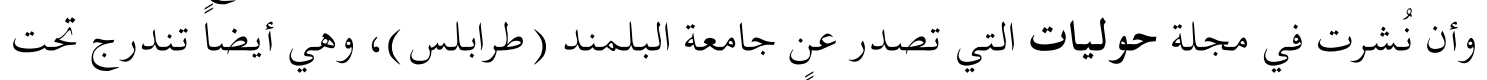

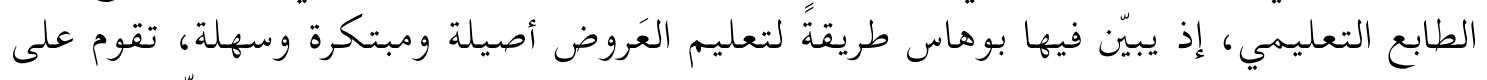

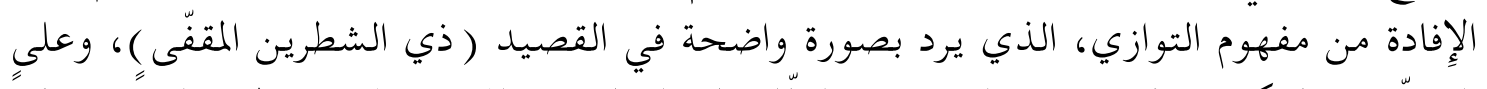

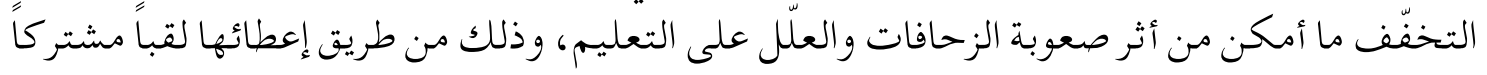

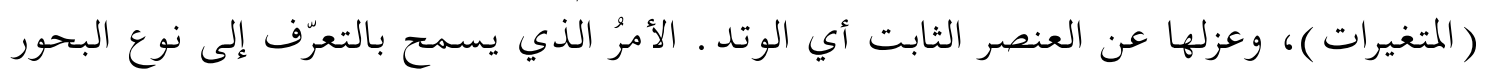
الشعريّة بسرعة وفعاليّة.

ولا بدّ من القول أخيراً إن التنوّع اللافت في المقالات المنشورة في هذا المجلد، تبيّن أن علم

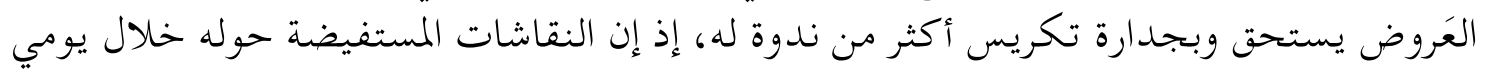




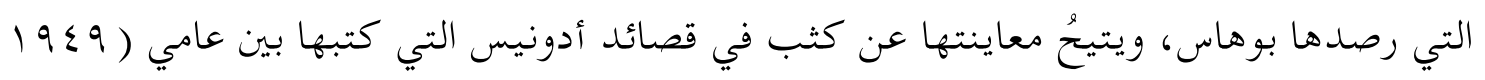
. ( 199$)^{-}$

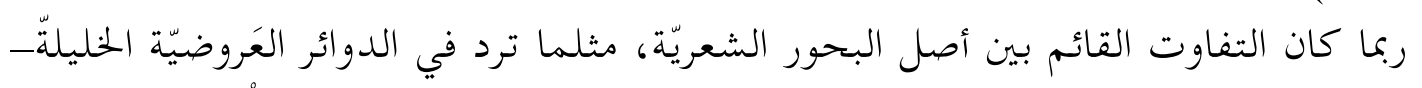

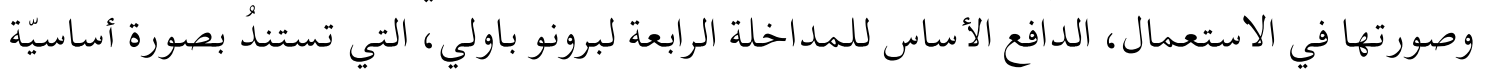

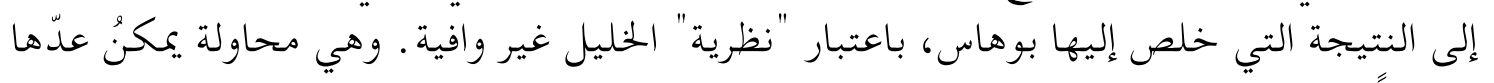

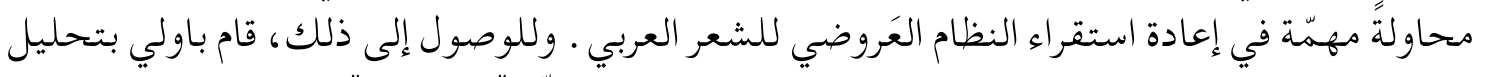

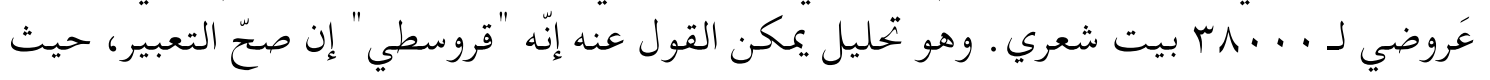

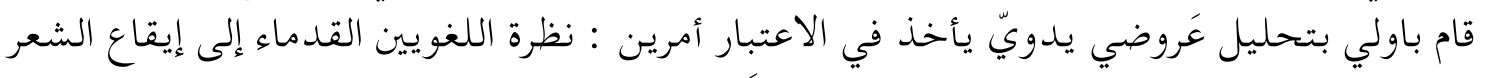

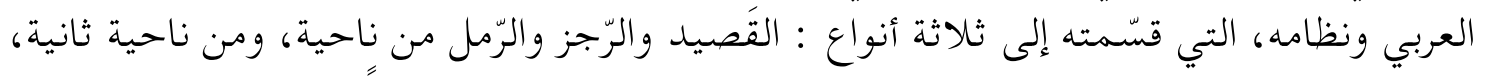

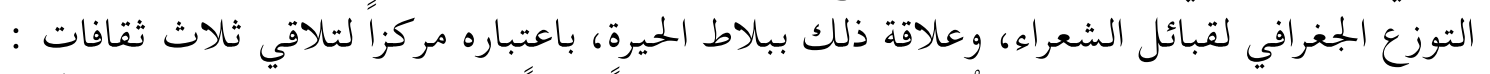

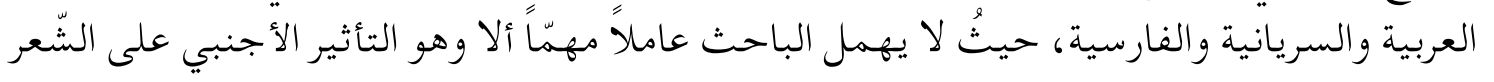

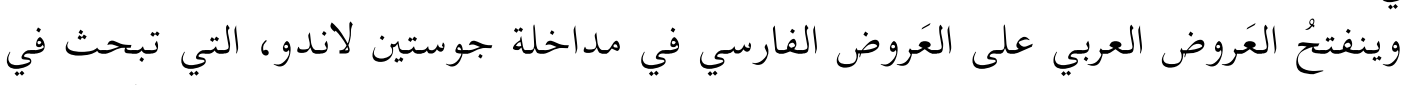

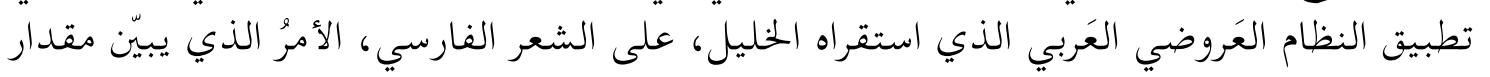

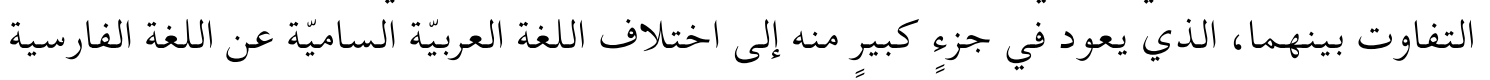

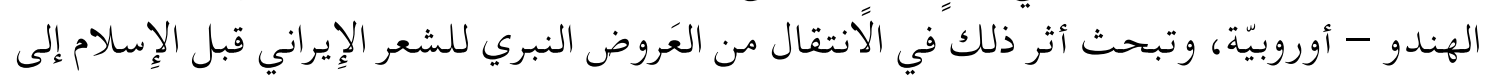

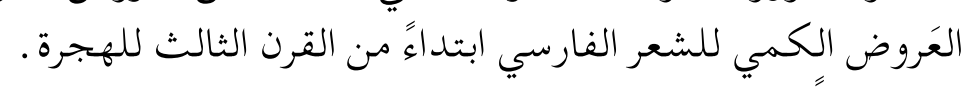

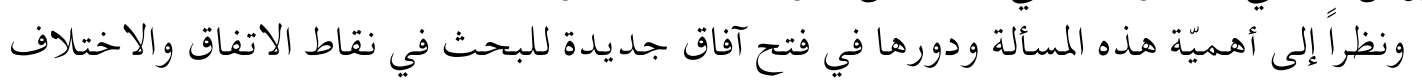

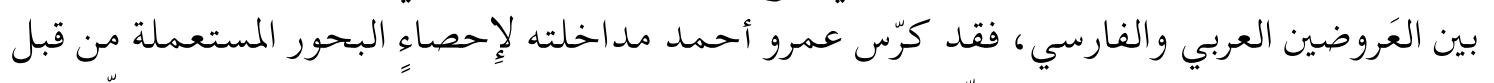

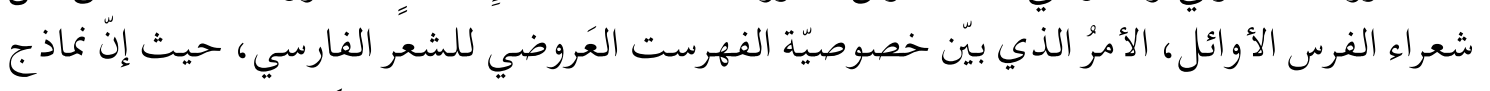

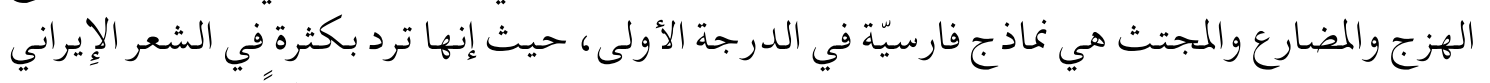

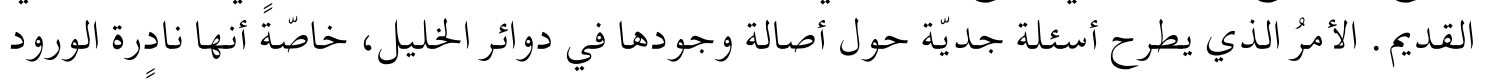

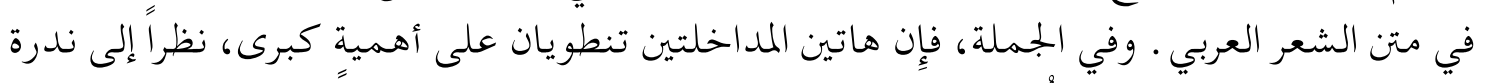

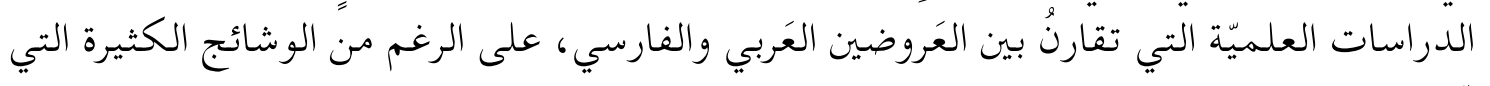

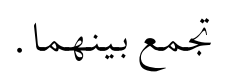

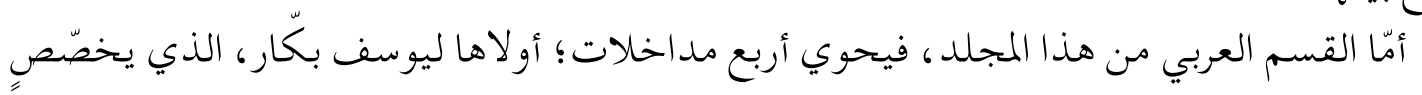

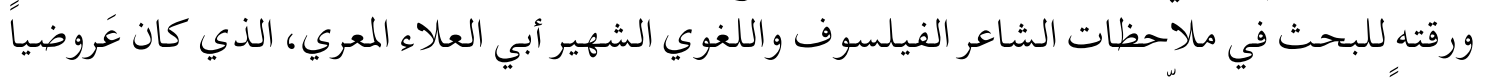

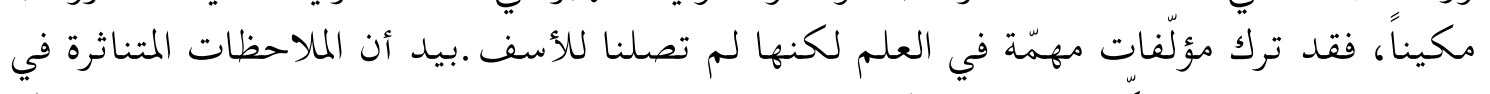

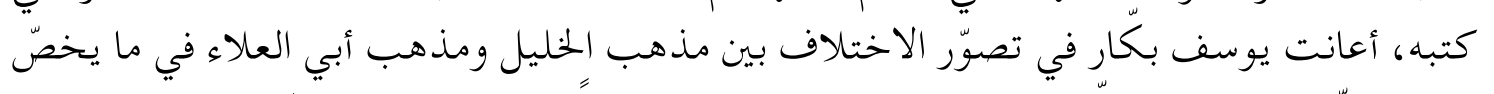

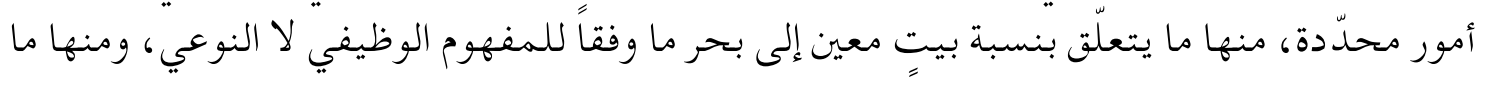




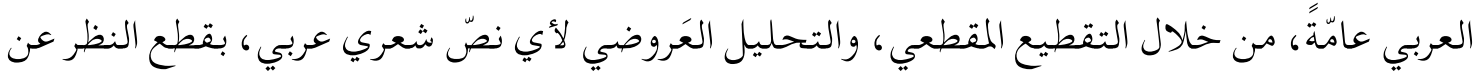

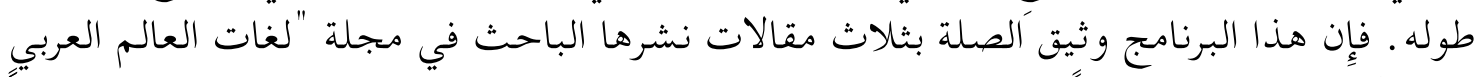

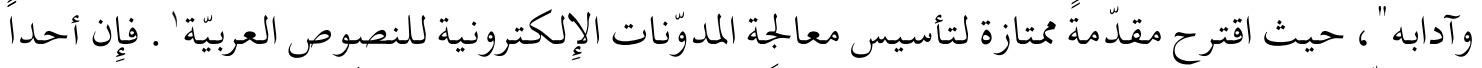

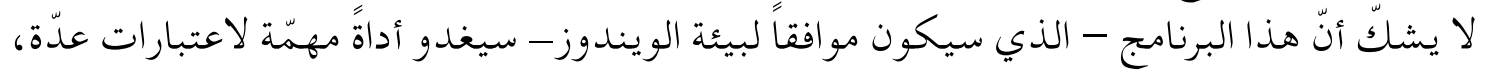

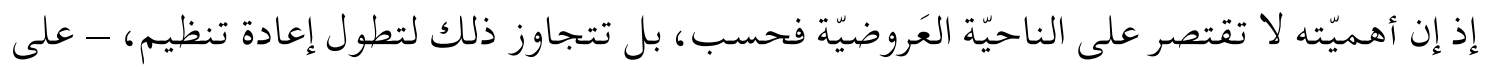

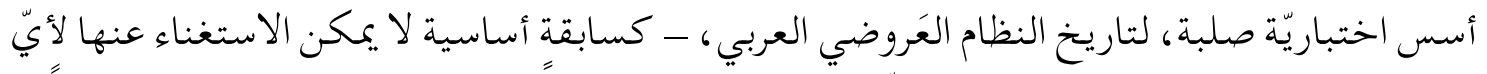

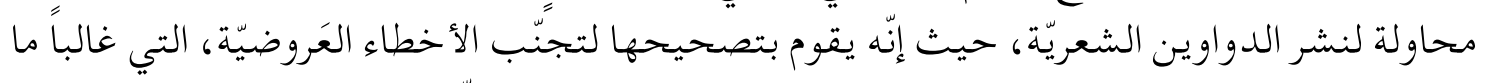

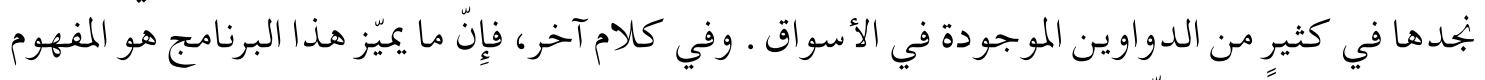

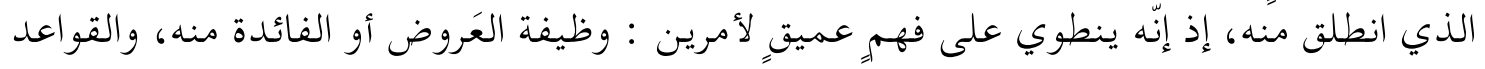

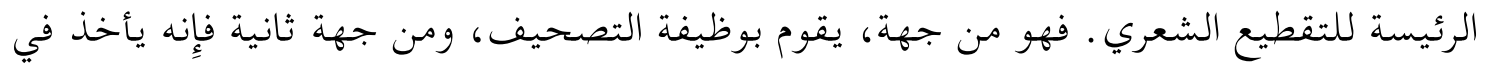

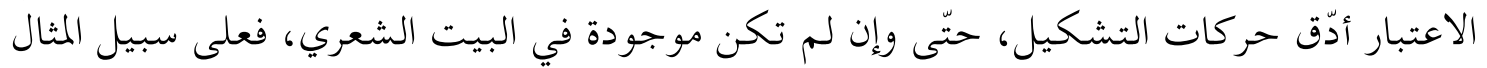

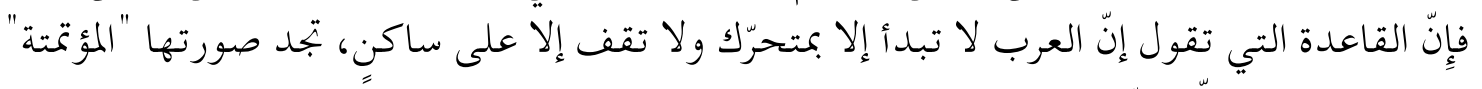

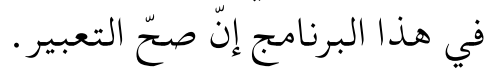

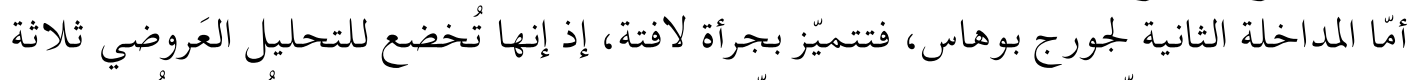

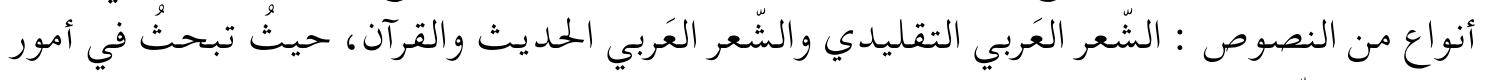

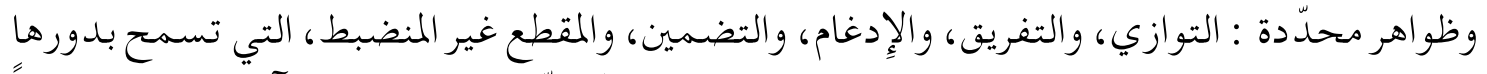

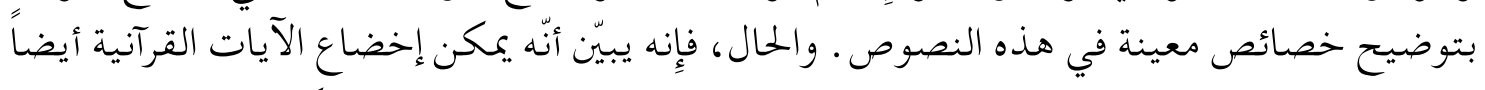

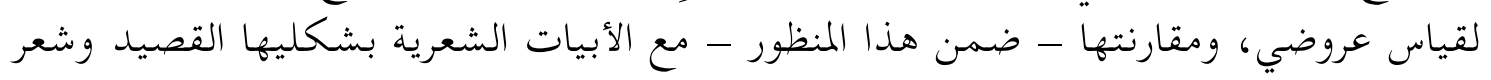

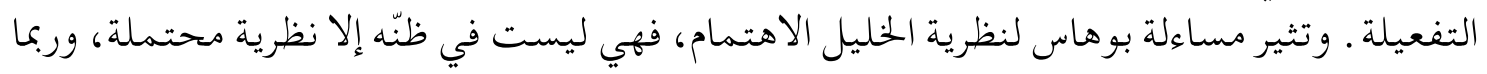

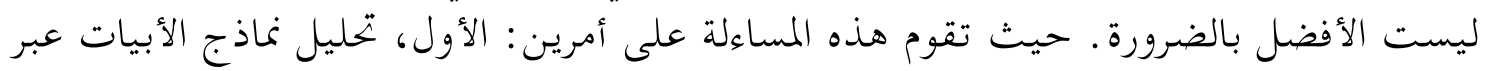

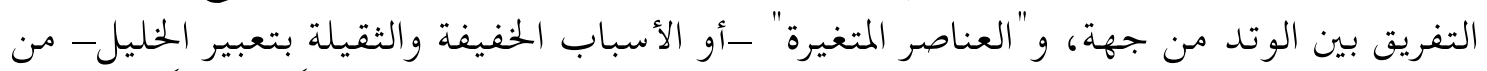

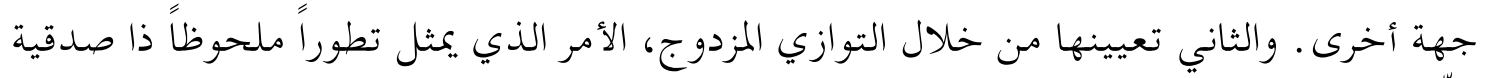
أقلّه إلى اليوم.

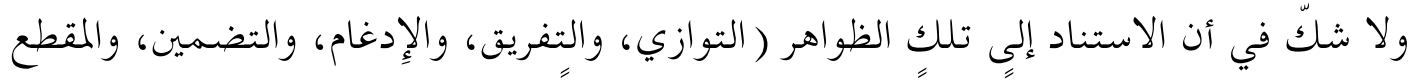

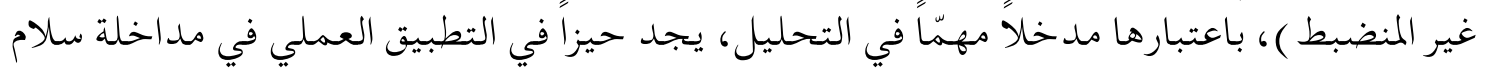

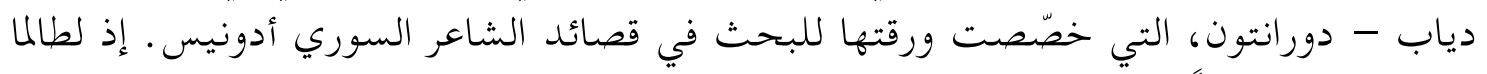

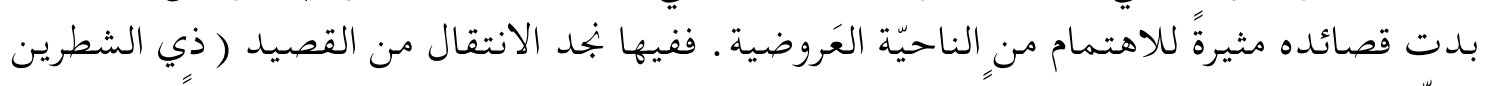

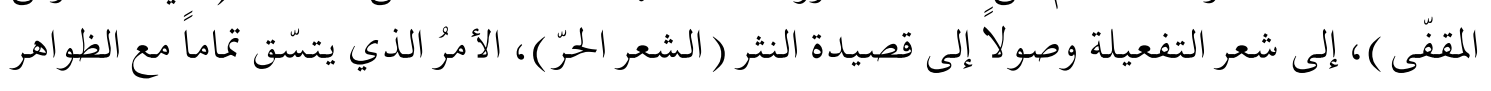

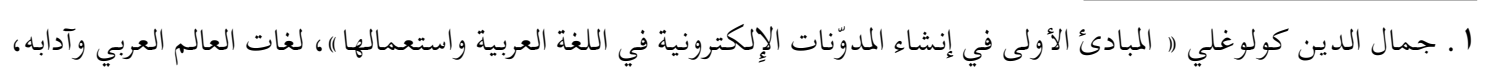

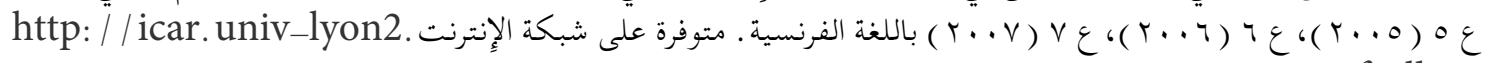
fr/llma 


\section{العروض العربي في القرن الثالث عشر بعد الخليل بين التقليد و التجديد يـ \\ ديمة الشكر ( المعهد الفرنسي للشرق الأدنى، دمشق )

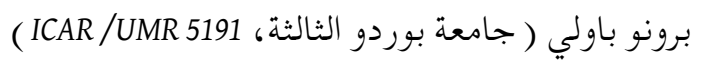

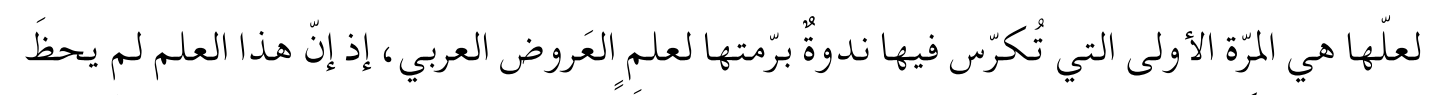

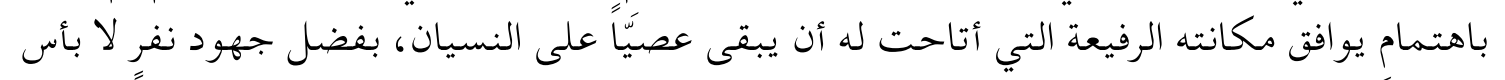

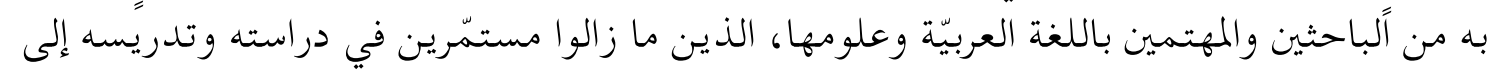

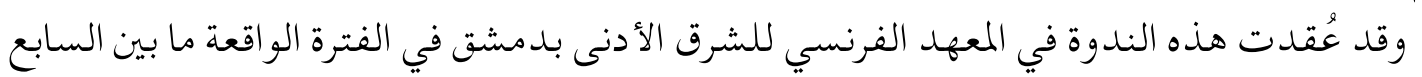

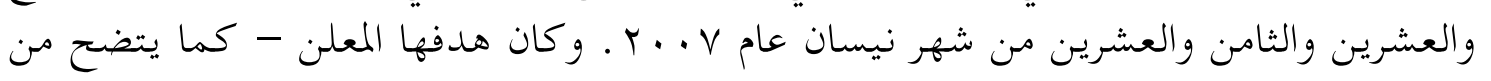

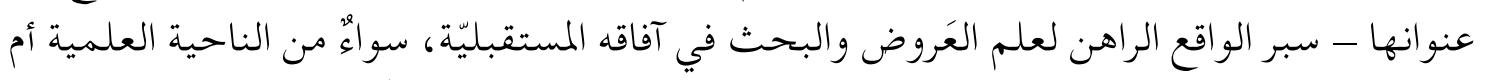

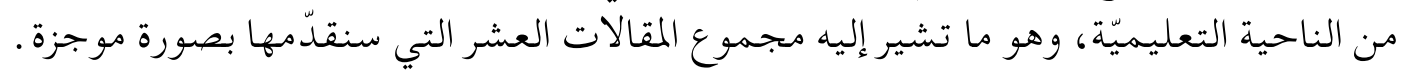

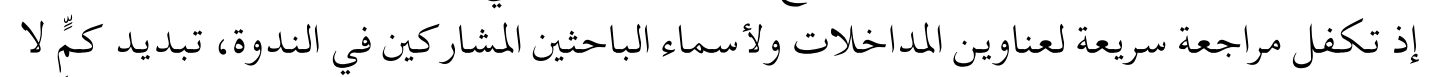

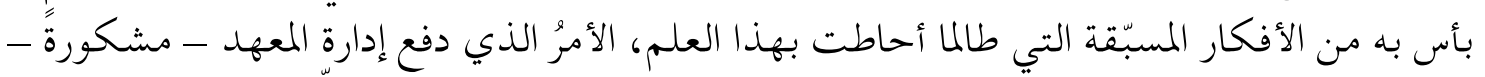

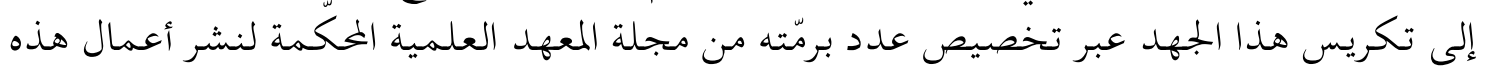
الندوة.

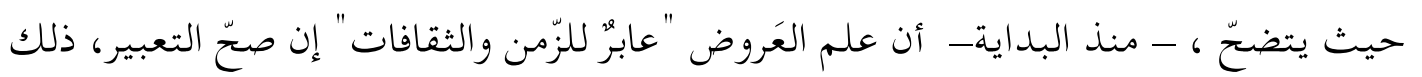

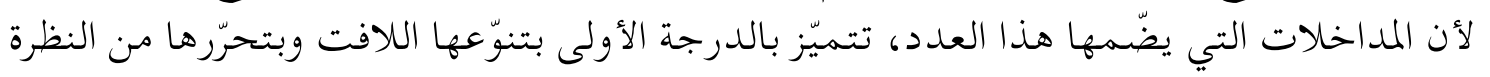

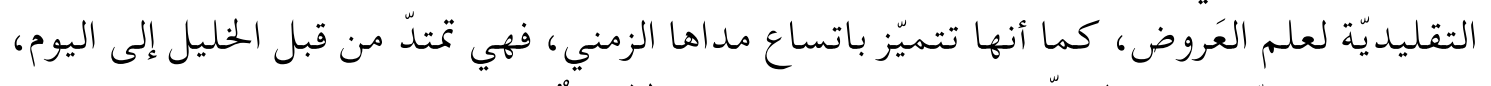

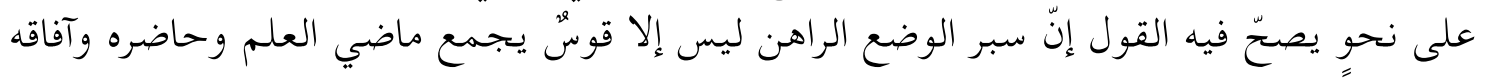

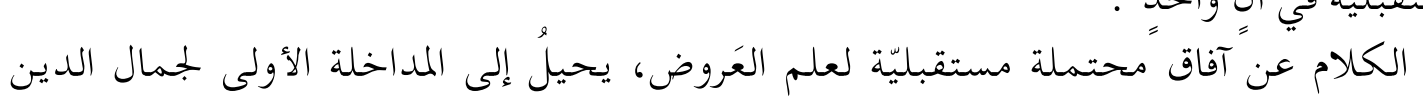

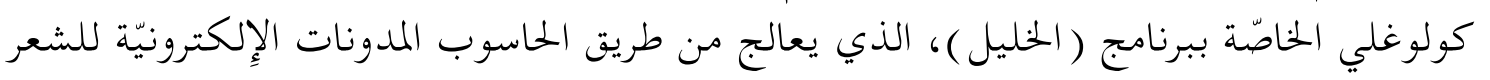

